\title{
Media Representations of Latina/os and Latino Students' Stereotype Threat Behavior
}

\section{Joseph Erba}

To cite this article: Joseph Erba (2018) Media Representations of Latina/os and Latino Students' Stereotype Threat Behavior, Howard Journal of Communications, 29:1, 83-102, DOI: 10.1080/10646175.2017.1327377

To link to this article: https://doi.org/10.1080/10646175.2017.1327377

册 Published online: 15 Jun 2017.

Submit your article to this journal $\pi$

Щ Article views: 291

Q View related articles $\sqsubset$

View Crossmark data $[ح$ 


\title{
Media Representations of Latina/os and Latino Students' Stereotype Threat Behavior
}

\author{
Joseph Erba
}

William Allen White School of Journalism and Mass Communications, University of Kansas, Lawrence, Kansas, USA

\begin{abstract}
This study explores how media representations of Latina/os and the level of ethnic identification of Latino (male) students influence how Latino college students at a predominantly White university interpret these media representations and the role they play when interacting with non-Latina/o students. Findings from in-depth interviews with Latino students reveal that Latinos who strongly identify with their Latina/o heritage (high-identifying) are likely to believe that non-Latina/o students view them through the lens of stereotypical media representations of Latina/os, and to consciously change their behavior in the presence of non-Latina/o students in an attempt to counter these stereotypes. On the other hand, Latinos who do not strongly identify with their Latina/o heritage (low-identifying) do not believe that other students associate them with media stereotypes and do not feel the need to change their behavior when interacting with non-Latina/o students. Findings suggest that media images of Latina/os influence the college experiences of high-identifying Latino students, while the same images do not influence the experiences of low-identifying Latino students. It discusses the relationships between media images and stereotype threat behavior and proposes recommendations universities can implement to enhance the experiences of these students.
\end{abstract}

\section{KEYTERMS}

Latina/os; media representations; stereotype threat; inter-racial/ethnic interactions; in-depth interviews

Media scholars have argued that media representations of racial/ethnic minority groups can influence how audiences perceive members of these groups (Grossberg, Wartella, Whitney, \& Wise, 2006). Indeed, studies have demonstrated a relationship between exposure to media portrayals of Latina/os and perceptions of Latina/os in general (Fujioka, 2011; Mastro, Behm-Morawitz, \& Ortiz, 2007; Mastro, Tukachinsky, Behm-Morawitz, \& Blecha, 2014; Valentino, Brader, \& Jardina, 2013). Media representations of Latina/os are usually stereotypical, with few instances of counterstereotypical images (Catalano \& Waugh, 2013; Mastro, 2009; Nielsen, 2013). A

CONTACT Joseph Erba erba@ku.edu W William Allen White School of Journalism and Mass Communications, University of Kansas, Stauffer-Flint Hall, Lawrence, KS 66045.

I would like to thank Dr. Lucila Vargas for her guidance and feedback throughout this project, Dr. Rosemary Ndolo for her substantive editorial assistance, and the five anonymous reviewers for their extremely thorough and useful comments. 
growing line of research has found that media stereotypes affect how Latina/o audience members perceive themselves and have emphasized the need for more research exploring how Latina/o audiences interpret and make sense of media images (López \& Chesney-Lind, 2014; Martinez \& Ramasubramanian, 2014). Stereotypes can also affect how members of racial/ethnic minority groups behave when faced with a situation in which they believe their behavior may confirm a stereotype about their group, a phenomenon known as stereotype threat (Steele \& Aronson, 1995). Briefly, and as further explained below, Latina/os who think that others may perceive them in terms of media stereotypes may find themselves in a stereotype threat position and may change their behavior to counter media stereotypes.

The present study aims to investigate the relationship between media representations of Latina/os and Latino college students' experiences at a predominantly White university. This study focuses on Latino (male) students because, despite belonging to the largest racial/ethnic minority group in the United States, Latinos have one of the lowest college graduation rates (U.S. Department of Education, 2014). Indeed, whereas Latina/os represent $17.4 \%$ of the U.S. population (U.S. Census Bureau, 2015), only $11.2 \%$ of Bachelor's degrees from U.S. universities in 2014 were conferred to Latina/o students, with Latinas (female) consistently graduating at higher rates than Latinos since the 1990s (U.S. Department of Education, 2015). Such low rates of graduation for Latinos and the gender discrepancies led Saenz and Ponjuan (2009) to note that "Latino males [were] effectively vanishing from the American higher education pipeline" (p. 54). Research exploring gender differences in the academic experiences of Latinos and Latinas found that Latina students attending predominantly White universities reported more positive perceptions of the university environment than did Latino students (Bordes \& Arredondo, 2005). Moreover, Latino students reported feeling greater academic discouragement and racial discrimination (Lopez, 1995) and were particularly affected by racism on campus (Hall \& Rowen, 2001). Given this context, and compounded by the dearth of studies focused on Latino students in higher education, this study aimed to explore the influence media messages have on a sample of Latino college students.

Researchers have shown that the level of ethnic identification play a role in the academic experiences of Latina/os in predominantly White institutions of higher educations (Flores Niemann, Romero, \& Arbona, 2000; Telzer \& Vazquez Garcia, 2009). The level of racial/ethnic identification has also been shown to play an important role in stereotype threat behavior, whereby those who identify more strongly with their racial/ethnic group are more likely to display stereotype threat behavior (Armenta, 2010; Ho \& Sidanius, 2010). Therefore, it is important to consider levels of racial/ethnic identification when evaluating the role of media in the experiences of members of these minority groups, yet most such studies often conceptualize racial/ethnic minority participants as a homogenous group and overlook in-group differences (Mastro, 2009).

This study aims to fill this gap by investigating how Latino students, all born in the United States from Latina/o parents but who either strongly identify with their Latina/o heritage (high-identifying [HI]) or do not strongly identify with 
their heritage (low-identifying [LI]), perceive the role media representations of Latina/os play in their college experiences. To this end, this study uses a stereotype threat framework to explore the role Latino students think media representations of Latina/os play in non-Latina/o students' perceptions of them and other Latino students (RQ1), and the relationship between media representations of Latina/os and Latino students' interactions with their non-Latina/o peers (RQ2).

\section{Literature review}

\section{Latina/os in news and entertainment media}

Latino males in the news are more likely than Whites to be portrayed as perpetrators of crime, whereas Whites are more likely to be portrayed as defenders of the law (Dixon \& Linz, 2000; McConnell, 2011). Representations of Latinos in the news are also dominated by images of immigrants, referred to as "illegal aliens" or "illegal immigrants," generally threatening U.S. domestic populations (Chávez, 2008; Mastro et al., 2014; Steinberg, 2004), as a "brown tide rising" of dangerous waters about to wash away U.S. society (Santa Ana, 2002). Nevertheless, news media have been enhancing their representations of Latina/os by including more coverage of collective actions and community events (Okamoto, Ebert, \& Violet, 2011).

Latina/os also continue to be stereotyped in entertainment media, with characters of little substance being prevalent (Merskin, 2007; Rodríguez, 2008; Valdivia, 2010). Overall, Latino male characters in television shows are mostly depicted as criminals, as well as lazier and less intelligent than White characters, with the main attribute of both Latina and Latino characters in these shows being their body (Mastro \& BehmMorawitz, 2005; Mastro \& Greenberg, 2000). Ramírez-Berg (2002) stated that old stereotypes of Latino males in movies have evolved into modern stereotypes based on societal changes; "El bandido" (the bandit) for example, has been replaced by a gang member. Rodríguez (2008) posited that in the media, Latinos are usually hottempered, knife-carrying delinquents, whereas Latinas are either portrayed as selfsacrificing, with virginal qualities, or as manipulative sexual temptresses. Rodríguez referred to this portrayal as the classic Hollywood "Latino cocktail" (p. 121).

In her report on the state of Latina/os in the media, Negrón-Muntaner (2014) found that "stereotypical storylines and characters that were coded as criminals, law enforcers, and blue-collar workers continue to dominate television shows, movies, and news" for Latinos (p. 16), whereas Latinas mainly play sexy or housemaid characters. Even the most popular user-generated YouTube videos reproduced criminal and unintelligent stereotypical portrayals, as Guo and Harlow (2014) reported that only one video did not use Latina/o stereotypes out of more than 100 videos featuring Latina/o characters.

Media studies focusing on Latina/o audiences' interpretations of media images and the role these images play in their lives are rare (Martinez \& Ramasubramanian, 2014; Valdivia, 2010). Rivadeneyra, Ward, and Gordon (2007) found a negative correlation between Latina/o adolescents' consumption of English-language 
mainstream media and their self-esteem levels. Qualitative studies focusing on Latina participants found that Latinas believe, to different degrees, that media portrayals of them can play a role in how they perceive themselves (Vargas, 2009) and how others interact with them (Rojas, 2004). Although Latinas who were interviewed in these studies provided various interpretations of media images, all recognized the stereotypical representations of Latinas and displayed concerns about them. Rivadeneyra (2006) also found that Latina/o adolescents were aware of stereotypical representations of Latina/os but cautioned that individual differences should be taken into account when exploring audiences' interpretations of media images. This present study uses a stereotype threat framework to explore how Latinos with different levels of ethnic identification perceive the role media images play in their interactions with non-Latina/o students.

\section{Stereotype threat}

The theory of stereotype threat posits that members of a particular group may be overly pressured to counteract the potential confirmation of these stereotypes when faced with judgment based on an attribute with stereotyping implications (Steele \& Aronson, 1995). In other words, people may consciously change their behavior to avoid acting in a way that may be perceived as confirming a stereotype about their group. Stereotype threat was first investigated by Steele and Aronson (1995) in exploring the achievement gap between White American and African American students. They hypothesized that under pressure to perform well on tests, African American students would be so anxious about confirming stereotypes associated with their group that it would negatively affect their results. When they presented African American students with a test stating that results would serve as a "diagnostic of intellectual ability," African American students performed significantly worse than when presented with the same test stating that results would serve to investigate the "psychological factors involved in solving verbal problems" (Steele \& Aronson, 1995, p. 799). Steele and Aronson referred to this phenomenon as "stereotype threat."

Researchers have explored how stereotype threat specifically applies to Latina/os. Gonzales, Blanton, and Williams (2002) conducted the first stereotype threat study involving Latina/o students and compared their test performances to that of White students. Similar to Steele and Aronson's (1995) initial study, they found that "Latinos exhibited depressed test performance in the diagnostic condition [intellectual ability] relative to controls [no reference to ability]" (Gonzales et al., 2002, p. 666). Other studies replicated these results and concluded that stereotype threat affects African Americans and Latina/os in similar ways (Nadler \& Clark, 2011; Schmader \& Johns, 2003). Stereotype threat has expanded beyond education to explore other situations when members of a particular group feel at risk of confirming a stereotype about their group (Bergeron, Block, \& Echtenkamp, 2006; Goff, Steele, \& Davies, 2008).

Stereotype threat, however, does not affect all members of one group in similar ways. Those who strongly identify with their group are more likely to display 
stereotype threat behavior than those who do not identify as strongly with their group (Armenta, 2010; Ho \& Sidanius, 2010). Ployhart, Ziegert, and McFarland (2003) demonstrated that "racial identity is the primary driver of perceptions of stereotype threat" (p. 253).

\section{Ethnic identity and social identity theory}

Martinez and Ramasubramanian (2014) found that Latino college students with different levels of ethnic identity reacted differently to comedy sketches that included stereotypical jokes. HI Latinos rated the jokes as being significantly more stereotypical than LI Latinos did. Furthermore, HI Latinos were also significantly more critical of a White comedian performing the stereotypical sketch than of a Latino comedian performing the same sketch, whereas LI Latinos perceived both comedians similarly. In other studies, HI Hispanics were also more likely than LI Hispanics to select television programs that reinforced their ethnic identity (Abrams \& Giles, 2009) and to watch Spanish-language media (Deshpandé, Hoyer, \& Donthu, 1986).

Given the role that ethnic identification plays in audiences' interactions with media content, social identity theory (SIT) can help us explore the relationship between Latinos' level of ethnic identification and their interpretation of media images and subsequent behavior. SIT posited that people claim attributes that bring them closer to members of their own group and distinguish them from other groups (Tajfel \& Turner, 1979). Accordingly, social identity derives from awareness of one's membership in a social group (or groups) together with the value and emotional significance attached to that membership (Tajfel, 1978). In the context of this study, HI Latinos consider their Latino heritage as a major aspect of their social identity (they may identify as Latinos above other identity markers such as social class or education), whereas LI Latinos do not define their social identity based on their Latino heritage (they may consider their identity as being a student at a particular university or majoring in a specific discipline to be more salient than their ethnic identity).

In sum, the studies discussed above reveal that media representations of Latina/os can influence how non-Latina/os perceive Latina/os and that the fear of reproducing stereotypes can influence behavior. Keeping in mind the role that ethnic identification plays in stereotype threat, this study contributes to our understanding of Latino audiences' interpretations of media images by examining how media representations of Latina/os affect Latino college students with different levels of ethnic identification.

\section{Method}

Data for this study were collected by conducting 35 in-depth interviews with 12 U.Sborn undergraduate Latino students attending a large, 4-year, predominantly White public university, hereafter referred to as South Eastern Public University (SEPU). ${ }^{1}$ This study only focused on Latino male students, as previous research has revealed 
gender differences among Latina/o students at predominantly White universities, with Latino students facing more challenges than Latina students. Participants took part in individual, face-to-face, semistructured, audiorecorded in-depth interviews approved by the university's Institutional Review Board. Interviews were conducted by the author, who is a non-Latino, cisgender male (male assigned male at birth) born and raised in Southern Europe by a family of immigrants and who did not complete his undergraduate studies in the United States. In interactions with participants, the interviewer was therefore outgroup in terms of ethnicity but possibly ingroup in terms of family immigration history.

All potential participants were first contacted via email, and those who were interested in taking part in the study confirmed that they self-identified as Latinos, were born in the United States and both of their parents were Latina/os. Participant recruitment was based on the assumption that HI Latinos would be actively engaged with Latino student organizations and that LI Latinos would be engaged in general student organizations, that is, not racially/ethnically oriented. Therefore, HI Latinos were recruited using a convenient purposive sample via the leadership of the main Latino organization on campus, whereas LI Latinos were recruited from the online membership list of nonracially/ethnically oriented organizations, such as historically White fraternities, based on their last name. ${ }^{2}$ A total of 30 Latino students were contacted for this study. Of these, nine were not interested in being interviewed, eight were not born in the United States, and one had a parent who was not Latina/o. Overall, participants represented a heterogeneous sample in terms of U.S. place of birth, economic background, and parents' nationalities (see Table 1).

Once the initial participants had agreed to take part in the study, interviews began, while additional participants were being recruited. Recruitment stopped when, based on initial data analysis, the data being collected from both groups of participants no longer yielded any new information, which demonstrated data saturation, a qualitative research concept that refers to the point at which enough information has been collected to replicate the study (Fusch \& Ness, 2015). There is no

Table 1. Participants' Characteristics.

\begin{tabular}{lllclc}
\hline Participants & ID & Family's ethnic heritage & U.S. state of birth & Social class & First-generation college student \\
\hline Alejandro $^{\text {a }}$ & LI & Puerto Rican & GA & Upper & No \\
Arturo & HI & Salvadoran & NY & Working & Yes \\
Cristian & LI & Mexican & FL & Working & Yes \\
Eduardo & HI & Mexican & CA & Middle & Yes \\
Enrique & LI & Mexican & FL & Upper & No \\
Federico & HI & Puerto Rican \& Cuban & NC & Middle & No \\
Hernando & HI & Puerto Rican & PR & Middle & No \\
Javier & LI & Puerto Rican & NY & Middle & No \\
Leonardo & LI & Honduran & NJ & Middle & Yes \\
Mauricio & HI & Mexican & TX & Working & Yes \\
Miguel & HI & Dominican & NY & Working & Yes \\
Ricardo & LI & Mexican & NC & Working & Yes \\
\hline
\end{tabular}

Note. $\mathrm{HI}=$ high-identifying; $\mathrm{LI}=$ low-identifying.

${ }^{a}$ Alejandro and Javier were the only participants who were not fluent in Spanish. 
formula or set number of participants to reach data saturation, as it depends on a study's research questions, with data collection and participant recruitment continuing until "depth as well as breadth of information is achieved" (O'Reilly \& Parker, 2012 , p. 3). More time spent with each participant is more likely to meet this goal than a larger number of participants with shorter interviews (Marshall \& Rossman, 2011).

Three interviews were conducted to allow for follow-up questions during the data analysis, explore various themes without tiring participants, and enhance the overall richness of the data. All but one participant took part in three interviews. ${ }^{3}$ Each first interview started with open-ended questions adapted from Phinney's (1992) ethnic identity scale, asking participants to define themselves, the racial/ethnic make-up of their closest friends on campus, the role of Latina/o culture in their everyday life, and the importance of their Latina/o heritage to their identity. Participants' answers confirmed the aforementioned assumption regarding their level of ethnic identification. No pattern emerged between participants' characteristics and their ethnic identification. That is, participants' place of birth, socioeconomic status, and parents' education did not seem related to their ethnic identification. The two groupings for this study were solely based on participants' level of ethnic identification: half were HI Latinos and half were LI. In addition to participants' identity, the first interview dealt with growing up in the United States with immigrant parents, high school experiences, journey to college, past and present media diet, and ended with presentations of Latina/os in the media. The second interview went more in-depth into media images, focusing on the role these images have played in participants' identity construction, life and college experiences, especially their interactions with other students. The third interview continued to explore participants' perceptions of media images and their college experiences and inquired about participants' relationship with SEPU, such as their feelings about how SEPU treats Latina/o students, their thoughts on what SEPU does well and what it could do better. Interviews were conducted in private study rooms on campus, and participants were each assigned a pseudonym. Each interview lasted approximately $60 \mathrm{~min}$. The data of the study amounted to $40 \mathrm{hr}$ and $46 \mathrm{~min}$ of audiorecording and 1,358 double-spaced pages of transcript.

Data analysis was aided by ATLAS.ti, software that assists in organizing and making sense of large qualitative datasets. Participants' answers were first coded in chronological order during the data collection period using a combination of "open coding," identifying relevant themes line by line, and "focused coding," searching for specific themes to group them into categories (Charmaz, 2006; Emerson, Fretz, \& Shaw, 1995). After completing all 35 interviews, data were also coded using "theoretical coding," more analytical codes that offered additional insight into the relationship between media representations of Latina/os and participants' college experiences (Emerson et al., 1995). Table 2 presents the main categories and codes pertaining to the study's research questions based on participants' level of ethnic identification. 
Table 2. Main Categories and Codes for High- and Low-Identifying Latinos by Quote Frequency.

\begin{tabular}{|c|c|c|}
\hline \multirow[b]{2}{*}{ Topic } & \multicolumn{2}{|c|}{ Number of quotes } \\
\hline & Hls & Lls \\
\hline \multicolumn{3}{|l|}{ Latinos in media and audiences' minds } \\
\hline Perceiving Latinos in terms of their media portrayals & 81 & 56 \\
\hline Portrayals of Latina/os in entertainment media & 46 & 27 \\
\hline Attending college equates being lucky & 43 & 5 \\
\hline Portrayals of Latina/os in news media & 25 & 9 \\
\hline Lowering expectations of Latinos via media & 19 & 5 \\
\hline Misunderstanding Latina/o culture & 17 & 3 \\
\hline Equating Latinos with Mexicans & 14 & 1 \\
\hline Perceiving Latino students differently based on context & 4 & 12 \\
\hline \multicolumn{3}{|l|}{ College experiences } \\
\hline Being Latino affects everyday interactions & 53 & 8 \\
\hline Media do affect college experience & 34 & 23 \\
\hline Feeling discriminated against & 28 & 13 \\
\hline Experiencing social and academic isolation & 26 & 13 \\
\hline Media do not affect college experiences & 7 & 29 \\
\hline Media do not affect self-esteem & 12 & 15 \\
\hline Feeling integrated & 4 & 22 \\
\hline Feeling safe & 2 & 22 \\
\hline Media do affect self-esteem & 16 & 8 \\
\hline \multicolumn{3}{|l|}{ Performance } \\
\hline Interacting with other students varies based on race & 83 & 17 \\
\hline Interacting with Latinos can reduce stereotypes depending on context & 45 & 39 \\
\hline Behaving against the expectations of being Latinos & 33 & 13 \\
\hline Acting in a certain way because of media stereotypes & 33 & 10 \\
\hline Acting Latino & 18 & 7 \\
\hline Conforming to be taken seriously & 11 & 4 \\
\hline
\end{tabular}

Note. $\mathrm{HI}=$ high-identifying; $\mathrm{LI}=$ low-identifying.

\section{Findings}

\section{Participants' characteristics and media}

The abbreviations HI and LI refer to the high-identifying and low-identifying groups, respectively. Each first mention of a participant's name in a new paragraph is followed with these abbreviations in parentheses. All participants were U.S.-born Latinos and all their parents, except for one LI participant's father (Javier), were born outside mainland United States. Except for two LI participants (Alejandro and Javier), all participants grew up bilingual (Spanish-English) and all of them spoke with a standard American accent. It is important to note that all participants considered themselves Latino. Although researchers have pointed out that many Latina/os report their race as White (Alcoff, 2006; Rodríguez; 2008), participants in this study reported being proud of their Latina/o heritage. Alcoff (2006) posited that Latina/os view identity in terms of culture and nationality, thus moving away from a racialized identity toward a more ethnic identity. Miville (2010) defined ethnic identity as "an enduring, fundamental aspect of the self that includes a sense of membership in an ethnic group and the attitudes and feelings associated with that membership" (p. 244).

Participants had a similar media diet. They grew up watching English-language cartoons on television. As college students, they mostly watched sports games, talk shows, and comedies, referring to ESPN and Comedy Central as their favorite channels. They mainly used the Internet for school and social purposes, and all were 
active on social media sites such as Facebook. With regard to media representations, all participants were well-aware of the many stereotypes media use in their portrayals of Latina/os. Participants' references to media pertained to U.S. English media. All used similar terms to describe how Latina/os are typically portrayed in the media, and all of them described Latina/os in the media as being presented as one homogeneous group, lacking individual differences. However, HIs displayed higher levels of analysis of media images than LIs. Overall, participants used 45 words/terms to describe media stereotypes of Latina/os, such as criminal, gangsters, illegal, immigrants, maids, Mexicans, pregnancies, and sexy. HIs used such words/terms in the context of media representations twice as often as LIs, with 354 references versus 184. As participants described Latina/os in the media in terms of stereotypes, their responses need to be interpreted in the context of media being dominated by unfavorable representations of Latina/os.

Because of the study's focus on ethnic identification, findings are discussed by contrasting HIs' and LIs' answers vis-à-vis perceptions of Latina/o (students) and interactions with non-Latina/o students. It is important to keep in mind that all participants were men, and even though interview questions did not directly focus on their gender identity, their gender may nevertheless influence how they consume and make sense of media messages. All participants were also high-achieving students whose interpretations of media messages may be more critical than average (Latina/o) media consumers.

\section{Media representations and perceptions of Latina/o students (RQ1)}

\section{Responses from L/s}

The majority of LIs stated that their White peers perceive them as "really intelligent" students who are Latinos, to use Alejandro's (LI) words. According to LIs, media representations of Latina/os do not influence how they are perceived. They assumed that their White peers would recognize that their presence on campus was due to their academic achievements, given that SEPU is a selective university. As Cristian (LI) stated, "If you're here at [SEPU] ... you're obviously a smart kid." Ricardo (LI) said that White students perceive him in the same light as any other students on campus, "as equal," stating, "I don't think that they would see us differently, probably they would just see us as competition on real business jobs." He later reinforced this idea, stating and that "they would see me as an educated Latino who obviously has some intellect to be here [at SEPU]." These comments from LIs suggest they feel respected by and academically equal to their White peers.

Enrique (LI) was even more emphatic that his White peers see him as a highachieving student, stating that White students "see [him] as the cream of the crop," an expression he repeated five different times, and "as one that rose above the rest." When I asked Enrique if he thought media representations of Latina/os affected students' perceptions of Latina/o students, he responded: "the students would see the portrayals on media, see then the students on campus who are Latino, and be like 'okay, these are probably the top of the top, maybe like the top one percent."' 
Comparing himself to Latinos portrayed in the media, Enrique added, "everyone else is just doing much worse [academically] and those are the ones that you see on TV.' In his comment, Enrique uses media to justify his argument. According to him, how could White students not think that Latina/o students at SEPU are "the top of the top" when they see in the media that Latina/os are more likely to drop out of high school than to attend college.

The idea of being perceived as smart because of attending SEPU, regardless of contrary media representations, is consistent with Heider's (1944) attribution theory, whereby people attribute particular phenomena or circumstances to their actions. In this particular instance, such attribution is referred to as "impersonal causality," defined as "unintentional human behaviors" (Malle, 2008, p. 165); influencing perceptions is not the intent of LIs' high academic achievements but they attribute their White peers perceiving them differently than Latinos in the media to their academic achievements.

\section{Responses from HIs}

HIs were more likely than LIs to state that audiences perceived Latina/os in terms of unfavorable media stereotypes (157 quotes vs. 67, combining four codes pertaining to stereotypical perceptions). Similar to LIs, all HIs acknowledged that attending college was not the norm for Latinos; however, contrary to LIs' reasons, the majority of HIs explicitly mentioned that many of their White peers might attribute their presence at SEPU to affirmative action policies. For instance, Mauricio (HI) said that White students might think that Latina/o students who have been accepted at SEPU "got lucky," whereas Eduardo (HI) stated, "I think that people might think that I got in just because I'm Latino and that the school is just trying to diversify their student population." In this scenario, Latina/o students are far from being perceived as "the cream of the crop," as Enrique (LI) said earlier. Hernando (HI), who was the most vocal about White students perceiving Latina/o students as filling a "quota," added, "When white students look at other minority students here, they think, I know a bunch of them think about affirmative action." Hernando suggests that White students do not believe that ethnic/racial minorities possess the intellectual capabilities to study at a university as prestigious as SEPU. Miguel (HI) also commented on how White students may perceive Latina/o students as benefitting from affirmative action policies:

Maybe the way they [White students] see it is like "you've only made it this far because of affirmative action or something like that," like "the only reason you're here is because we have to admit Latinos." Or maybe, "he didn't work as hard to be here as I did" you know, "he just has that advantage because he's like colored" or something like that.

Miguel's (HI) comment hints at the resentment he thinks White students have toward Latina/o students if the former believe that Latina/os do not deserve to study at SEPU. Although HIs suggested that White students perceive them as intellectually inferior, LIs claimed that White students perceive them as equal. These two different perspectives influence how participants interact with their White peers. 


\section{Media representations and stereotype threat behavior (RQ2)}

\section{Responses from L/s}

Only two LIs (Cristian and Javier) said that they consciously changed their behavior in the presence of non-Latina/o students because they were concerned about validating stereotypes about Latina/os. For instance, Cristian said that if he would propose eating at a Mexican restaurant, his friends would respond, "oh of course you wanna go to a Mexican restaurant." He then added, "I avoid that stereotypical stuff I see in the media." In this situation, Cristian consciously changed his behavior to avoid reinforcing any stereotype his peers may hold about Latinos, thus displaying stereotype threat behavior.

Cristian and Javier were the exception; the majority of LIs did not see the need to act in any particular way when interacting with non-Latina/o students. LIs believe that non-Latina/os will recognize that stereotypical media representations of Latina/os do not apply to them simply by virtue of the fact that they are in school, as opposed to stereotypes of Latina/os as uneducated. LIs reported that just seeing Latina/o students on campus positively affected White students' perceptions of them and used the same reasoning when interacting with White students, as Leonardo (LI) stated, "I'm obviously not exactly what they portray in the media. Javier (LI) further explained:

I feel university students are just more exposed to more diversity so their only interaction with a Latino isn't going to be what they see in Scarface. They're going to be able to directly interact with another Latino so their view isn't going to be based solely on what they see on TV.

Javier (LI) believes that being "exposed to more diversity" is enough to prove media representations wrong. Enrique (LI) made a similar point about interpersonal interactions with others, broadening it to members of any group and taking a color-blind approach, stating:

I think everyone, when they're at this school and like, and most people before this school, they've already met so many people from different cultures and even if they're not best friends with them or more than acquaintances, they've gotten past that [stereotyping]. I guess it goes back to experience; you get to know that everyone is a human being. It doesn't really matter like where you come from.

Such interactions may indeed influence perceptions, as Emerson, Kimbro and Yancey (2002) found that even limited contact in multiracial settings can lead to stereotype reduction. Allport (1954) referred to this phenomenon as the "contact hypothesis," which posits that interpersonal interactions between members of minority and majority groups lead to stereotype reduction. For instance, Cristian (LI) stated, "I do feel I've met enough people that it breaks the stereotype and I think the same way for me, that people have met enough [Latina/o] people that don't fit that mold." According to him, the burden to change students' perceptions of Latina/os in general does not rest on his shoulders because past Latina/o students have already dealt with it. Alejandro (LI) explained how people might change their perceptions of him: 
When I meet people and then they hear my name they might initially think like, "oh he's Hispanic" and then they have whatever ideas they have, but then I think like I said before, the personal experience of meeting someone, I think like most of the people I've met, once they get to know me, once I meet them then they realize like, "he doesn't fit the stereotype that I have" or they kind of just, they make their own judgments about me rather than based on what they already knew.

Alejandro's (LI) comment suggests he is aware that people have a preconceived image of Latina/os that may be triggered by his name. Despite his observation, nothing in our discussions suggested that he was actively trying to change people's perceptions of Latina/os. Similar to other LIs, Alejandro does not change his behavior when interacting with non-Latina/os because he assumes that being himself is enough to break any stereotypical views others may hold about him.

The above discussion suggests that LIs are not concerned about non-Latina/o students' perceptions of Latina/os. In their study on identity perception, Ho and Sidanius (2010) found that "students who do not believe others hold the negative stereotype about their group would be less concerned about being perceived in terms of the negative stereotype" concerning their group (p. 61). LIs' comments reflect such findings.

\section{Responses from HIs}

All HIs said they often consciously changed their behavior in the presence of nonLatina/o students, especially White ones, because they were concerned about validating stereotypes about Latina/os. Eduardo (HI) used eating out with friends to illustrate how he controls himself in certain situations, stating, "If I was with my white friends and we were trying to get something to eat, I probably wouldn't necessarily say a Latin food or Hispanic food would be one of my top choices just because of the people I'm with." This illustrates the phenomenon of stereotype threat, as Eduardo consciously changes his behavior in the presence of his White peers to avoid reinforcing any stereotype White students may hold about Latina/os. HIs mentioned instances pertaining to stereotype threat behavior much more frequently than LIs (44 quotes vs. 14, combining two codes pertaining to stereotype threat). In his study with high school and college students, Steele (1997) noted that only students who perceived school achievement to be part of their identity displayed stereotype threat attitudes. In this study, all participants were high-achievers and proud of their academic performances. However, ethnic identity is so salient that it surpasses identifying with school achievement as a factor in display of stereotype threat behavior.

HIs explained that they altered how they would otherwise behave with close friends, Latina/o or non-Latina/o, because they did not want their behavior to confirm stereotypes students may hold of Latina/os. Talking about media representations of Latina/os, Arturo (HI) stated, "to me it's just more motivation to prove people wrong." Similarly, Federico (HI) explained how media stereotyping "drives [him] to be different and show, prove to people otherwise" and how he believes that his behavior influences perceptions of Latinos: "I feel like I change people's views on 
the stereotypical Latino, or Latinos in general, they'll be like 'Oh, Federico's a Latino and he doesn't do this' or 'Federico's a Latino and he does do this." HIs reiterated their belief in the relationship between media representations of Latina/os and students' stereotypical perceptions of Latina/os. Miguel (HI) explained how these media portrayals put him at risk of stereotype threat:

Anything, I feel will cause someone to associate me with the media portrayal. I can act a particular way so I can be on someone's good side and they can, their image of me can be very positive until I do one thing that makes them associate me with media portrayals and then it's just like "oh, Miguel, he's just a typical Latino that I see on TV." So I mean, I feel like I always act in order to defy media portrayals, in order to defy stereotypes.

Laar, Levin, and Sinclair (2008) labeled the phenomenon displayed by Miguel (HI) personal identity stereotype threat, which is "the concern that the self may be harmed by the stereotype and that stereotypic beliefs about the group will be confirmed in the self" (p. 297). Even though HIs know they do not fit how media portray Latina/os, media images nevertheless compel them to display stereotype threat behavior. Eduardo (HI) provided another concrete example:

With my Latin friends, listening to different types of music, I'll probably do the footsteps for a dance, whereas when I'm around white friends, I wouldn't necessarily do that because I guess they're not used to listening to that music or to seeing people just dancing, and I wouldn't want to reinforce that stereotype that all Latinos dance.

In this situation, Eduardo (HI) restrains from fully being himself because he thinks he is at risk of confirming a stereotype. He worries that his non-Latina/o peers will see dancing as an inherent characteristic of all Latina/os. Hernando (HI) also illustrated how stereotype threat affects his interactions with White students, stating, "I feel like I have to act better than what they [White students] see [in the media]. I have to act, in a sense, hold back on my Hispanic attributes I guess." He mentioned his voice as one of his "Hispanic attributes" he "holds back on," stating, "in public, when I'm around people, I feel like I should have to calm that stuff down, I guess kind of lower my voice." Although Hernando's natural communication style could be considered as "elaborated," he changes to an "understated" or "succinct" one when talking with White students. The former refers to the use of rich language whereas the latter relies more on understatements and silence (Gudykunst \& TingToomey, 1988), as illustrated by Hernando's lowering his voice.

Media effects studies use explicit mentions/images of race/ethnicity in media messages to prime participants' racial/ethnic identity (e.g., Appiah, 2001; Forehand \& Deshpandé, 2001; White, 2007). Similarly, most stereotype threat studies prime participants' racial/ethnic identity simply by asking them to indicate their racial/ethnicity background at the beginning of a study. Participants who were made aware of their race/ethnicity displayed stronger stereotype threat behaviors. Because of the salience of their Latina/o heritage on their identity, HIs need not be reminded of their race/ethnicity and are more likely to display stereotype threat attitudes than LIs. For HIs, it seems that because of the salience of their ethnic identity, the presence of white students primes them to behave in ways consistent with stereotype threat. 
As Croizet, Desert, Dutrevis, and Leyens (2001) posited, "Stereotype threat is a general self-threat that triggers effortful attempts to restore a sense of self-integrity" (p. 306). Indeed, HIs respond to stereotype threat by aiming to correct media's misrepresentations of Latina/os.

Although both LIs and HIs believe that their actions can affect perceptions, LIs displayed characteristics of "impersonal causality" because although they do not act intentionally to influence perceptions of them, they believe that their academic achievements have the unintended consequence of favorably influencing perceptions of them. On the contrary, HIs attribute unfavorable perceptions about them to external factors such as media stereotypes and subsequently behave with "personal causality," defined as performing "an intentional action" (Malle, 2008, p. 165). Specifically, HIs consciously change how they act in the presence of their White peers hoping to counter media stereotypes and influence perceptions of Latina/os to be more favorable. Those comments from HIs echo comments from LIs pertaining to the contact hypothesis discussed above, as HIs also believe that interactions between Latina/o students and White students could influence how the latter perceive Latina/os. However, contrary to LIs who believe that their non-Latina/o peers had already interacted with enough Latina/os to not perceive Latina/o students in a stereotypical way, HIs feel that their peers hold stereotypical views of Latina/os and use peer interactions to counter such views.

In these interactions, HIs see themselves from the perspective of their White peers. This represents the concept of "double consciousness" that W.E.B. Du Bois (2007) theorized for African Americans who are "always looking at one's self through the eyes of others" (2007, p. 34). Similar to what HIs describe, Du Bois posited that Blacks in the United States live "a double life, with double thoughts, double duties, and double social classes" (p. 125). Bruce (1992) explained that Du Bois' double consciousness refers to "the real power of white stereotypes in black life and thought" (p. 301). Media stereotypes lead HIs to believe that they should act in ways that counter those stereotypes and that would be perceived as socially acceptable to their White peers. For example, changing their communication style to an understated style, which they think would be the norm for Whites.

\section{Conclusion}

Similar to other media studies with Latina/o participants (Martinez \& Ramasubramanian, 2014; Rivadeneyra, 2006; Vargas, 2009), findings from this study confirmed that Latino students, regardless of their level of ethnic identification were aware of the stereotypes media use about their group and how those stereotypes can paint an unfavorable picture of their group. The majority of media studies exploring Latina/os, as well as other racial/ethnic minority groups, tend to conceptualize members of those groups as homogeneous. However, the present study shows that differences in the level of racial/ethnic identification among high-achieving Latino college students plays an important role in the interpretation of and response to media messages. HIs think stereotypical media representations negatively affect how 
their non-Latina/o peers perceive them: that is, that they too will have these stereotypical attributes. In contrast, LIs think these same media representations positively affect how their non-Latina/o peers perceive them: that is, by being students at SEPU, they not only defy stereotypical representations but exceed expectations White peers may have of them based on negative media representations of Latina/os.

With regard to response to these media representations, all HIs consciously changed their behavior in the presence of their White peers to act in ways that they believe is more socially acceptable to Whites in hopes of countering media stereotypes, thus displaying stereotype threat behavior, whereas the majority of LIs did not change their behavior on campus, nor did they feel the need to. LIs did not believe that media stereotypes influence how their White peers perceive them; thus, they did not have any reason to disprove representations that they did not feel applied to them. The difference in response reveals that HIs are more prone to stereotype threat behavior and feel that the onus of correcting the potential influence of media stereotypes of Latina/os is on them. LIs do not appear to feel a similar pressure.

Despite the two different interpretations of and responses to media representations, both HIs and LIs refuse to internalize such representations vis-à-vis their identity, in that they do not allow media representations of Latina/os to define their identity. Not internalizing those images is particularly important because previous studies conducted with younger Latinas revealed that media images can influence how Latinas see themselves (Rojas, 2004; Vargas, 2009). In the present study, participants were adamant that media did not define what being Latino meant to them; this might be because their identity as high-achieving students is so salient that they do not internalize the Latina/o identity media present.

\section{Limitations}

Interpretations of these findings should take into account the fact that the data collection only relied on one type of interviewing at one university located in a Southeastern state, which does not have as rich a Latina/o culture as some other states may have. This study also focused only on a very specific segment of Latina/os in the United States, high-achieving male college students at a predominantly White university. Both of these factors limit the findings' transferability to other Latina/o demographics. In addition, interview questions did not directly address the role gender may play in interpreting and making sense of media messages. Future research should continue to explore ethnic identification within different samples of Latina/o audiences, for example, based on gender, education levels and social class.

\section{Recommendations}

It is unfortunate that because of stereotypical media representations, some Latino students feel the need to counter those stereotypes by changing the way they act. Given that mainstream media representations of Latina/os are not likely to change in the near future, universities should be aware of the role media representations 
play on the experiences of Latino students and take measures to address the consequences. One way of doing this could be to develop media literacy workshops to deconstruct stereotypical media representations. All students should be encouraged to attend media literacy workshops in order to critically analyze the construction and effects of media messages (Dennis, 2004). Such workshops would focus on making students aware of media stereotypes and the role they play in constructing identities about other groups. Workshops would also explain why stereotypes are used in media and their effects on audiences' perceptions of others. Understanding those concepts could limit future potential media effects and ideally lead to more favorable perceptions of members from other groups.

Universities could also support cultural competency trainings to counter stereotypical perceptions and expectations. All students should take part in cultural competency trainings to develop "a critical view of cultural differences, people's experiences of oppression and marginalization, class differences, discrimination, racism, and becoming aware of one's cultural biases" (Suarez-Balcazar et al., 2011, p. 5 ). The purpose of those trainings would be to introduce students to other cultures and perspectives, specifically focusing on cultural awareness, understanding and practice. Such initiatives would contribute to making campuses more welcoming while displaying institutional support for racial/racial minority students.

Both HIs and LIs stated that their interactions with non-Latina/o students can contribute to reducing stereotypical perceptions toward Latina/os, a phenomenon known as the contact hypothesis. However, "contact" among Latina/os and nonLatina/os need to be meaningful to influence perceptions. Indeed, Allport (1954) differentiated "casual contacts" from "true acquaintances," asserting that only the latter "lessen prejudices" (Allport, 1954, p. 264). Thus, it is questionable whether any interactions in which HIs are under stereotype threat would be meaningful in changing perceptions, given the casual nature of such interactions. However, media literacy workshops and cultural competency trainings could foster a climate of inclusion that might lower the threshold for meaningful contact and thus make even short interactions beneficial, as well as encourage students from diverse racial/ethnic backgrounds to form the true acquaintanceships needed for the contact hypothesis to counter stereotypical perceptions.

\section{Notes}

1. SEPU's undergraduate population is approximately $65 \%$ White and $7 \%$ Hispanic of any race.

2. Researchers have relied on Latina/o-serving organizations (Torres \& Ong, 2010) and Spanish surnames (Hamilton et al., 2009; Perez-Stable, Hiatt, Sabogal, \& Otero-Sabogal, 1995) to identify and recruit Latina/o participants.

3. One participant, Hernando, graduated with his Bachelor's degree before the end of the study.

\section{References}

Abrams, J. R., \& Giles, H. (2009). Hispanic television activity: Is it related to vitality perceptions? Communication Research Reports, 26(3), 247-252. 
Alcoff, L. (2006). Visible identities: Race, gender, and the self. Oxford, England: Oxford University Press.

Allport, G. W. (1954). The nature of prejudice. Cambridge, MA: Perseus Books.

Appiah, O. (2001). Ethnic identification on adolescents' evaluations of advertisements. Journal of Advertising Research, 41(5), 7-22.

Armenta, B. E. (2010). Stereotype boost and stereotype threat effects: The moderating role of ethnic identification. Cultural Diversity and Ethnic Minority Psychology, 16(1), 94-98.

Bergeron, D. M., Block, C. J., \& Echtenkamp, B. A. (2006). Disabling the able: Stereotype threat and women's work performance. Human Performance, 19(2), 133-158.

Bordes, V., \& Arredondo, P. (2005). Mentoring and 1st-source Latina/o college students. Journal of Hispanic Higher Education, 4(2), 114-133.

Bruce, D. D. (1992). W. E. B. Du Bois and the idea of double consciousness. American Literature, 64(2), 299-309.

Catalano, T., \& Waugh, L. R. (2013). The ideologies behind newspaper crime reports of Latinos and Wall Street/CEOs: A critical analysis of metonymy in text and image. Critical Discourse Studies, 10(4), 406-426.

Charmaz, K. (2006). Constructing grounded theory: A practical guide through qualitative analysis. Thousand Oaks, CA: Sage Publications.

Chávez, L. R. (2008). The Latino threat: Constructing immigrants, citizens, and the nation. Stanford, CA: Stanford University Press.

Croizet, J. C., Desert, M., Dutrevis, M., \& Leyens, J. P. (2001). Stereotype threat, social class, gender, and academic under-achievement: When our reputation catches up to us and takes over. Social Psychology of Education, 4(3/4), 295-310.

Dennis, E. E. (2004). Out of sight and out of mind the media literacy needs of grown-ups. American Behavioral Scientist, 48(2), 202-211.

Deshpandé, R., Hoyer, W. D., \& Donthu, N. (1986). The intensity of ethnic affiliation: A study of the sociology of Hispanic consumption. Journal of Consumer Research, 13(2), 214-220.

Dixon, T. J., \& Linz, D. (2000). Overrepresentation and underrepresentation of African Americans and Latinos as lawbreakers on television news. Journal of Communication, 50(2), 131-154.

Du Bois, W. E. B. (2007). The souls of Black folk. New York, NY: Oxford University Press.

Emerson, A. R., Fretz, R. I., \& Shaw, L. L. (1995). Writing ethnographic notes. Chicago, IL: The University of Chicago Press.

Emerson, M. O., Kimbro, R. T., \& Yancey, G. (2002). Contact theory extended: The effects of prior racial contact on current social ties. Social Science Quarterly, 83(3), 745-761.

Flores Niemann, F., Romero, A., \& Arbona C. (2000). Effects of cultural orientation on the perception of conflict between relationship and education goals for Mexican American college students. Hispanic Journal of Behavioral Sciences, 22(1), 46-63.

Forehand, M. R., \& Deshpandé, R. (2001). What we see makes us who we are: Priming ethnic self-awareness and advertising response. Journal of Marketing Research, 38(3), 336-348.

Fujioka, Y. (2011). Perceived threats and Latino immigrant attitudes: How White and African American college students respond to news coverage of Latino immigrants. Howard Journal of Communications, 22(1), 43-63.

Fusch, P. I., \& Ness, L. R. (2015). Are we there yet? Data saturation in qualitative research. The Qualitative Report, 20(9), 1408-1416.

Goff, P. A., Steele, C. M., \& Davies, P. G. (2008). The space between us: Stereotype threat and distance in interracial contexts. Journal of Personality and Social Psychology, 94(1), 91-107.

Gonzales, P. M., Blanton, H., \& Williams, K. J. (2002). The effects of stereotype threat and doubleminority status on the test performance of Latino women. Personality and Social Psychology Bulletin, 28(5), 659-670.

Grossberg, L., Wartella, E., Whitney, D. C., \& Wise, J. M. (2006). MediaMaking: Mass media in a popular culture. Thousand Oaks, CA: Sage. 
Gudykunst, W. B., \& Ting-Toomey, S. (1988). Culture and interpersonal communication. Thousand Oaks, CA: Sage.

Guo, L., \& Harlow, S. (2014). User-generated racism: An analysis of stereotypes of African Americans, Latinos, and Asians in YouTube videos. Howard Journal of Communications, 25, 281302.

Hall, R. E., \& Rowan, G. T. (2001). Hispanic-American males in higher education: A descriptive/qualitative analysis. Education, 121(3), 565-574.

Hamilton, A. S., Hofer, T. P., Hawley, S. T., Morrell, D., Leventhal, M., Deapen, D., ... \& Katz, S. J. (2009). Latinas and breast cancer outcomes: population-based sampling, ethnic identity, and acculturation assessment. Cancer Epidemiology Biomarkers \& Prevention, 18(7), 2022-2029.

Heider, F. (1944). Social perception and phenomenal causality. Psychological Review, 51(6), 358374.

Ho, A. K., \& Sidanius, J. (2010). Preserving positive identities: Public and private regard for one's ingroup and susceptibility to stereotype threat. Group Processes and Intergroup Relations, 13(1), 55-67.

Laar, C., Levin, S., \& Sinclair, S. (2008). Social identity and personal identity stereotype threat: The case of affirmative action. Basic and Applied Social Psychology, 30(4), 295-310.

Lopez, E. M. (1995). Challenges and resources of Mexican American students within the family, peer group, and university: Age and gender patterns. Hispanic Journal of Behavioral Sciences, 17(4), 499-508.

López, V., \& Chesney-Lind, M. (2014). Latina girls speak out: Stereotypes, gender and relationship dynamics. Latino Studies, 12(4), 527-549.

Malle, B. F. (2008). Fritz Heider's legacy: Celebrated insights, many of them misunderstood. Social Psychology, 39(3), 163-173.

Marshall, C., \& Rossman, G. B. (2011). Designing qualitative research (5th ed.). Thousand Oaks, CA: Sage Publications.

Martinez, A. R., \& Ramasubramanian, S. (2014). Latino audiences, racial/ethnic identification, and responses to stereotypical comedy. Mass Communication and Society, 18(2), 209-229.

Mastro, D. E. (2009). Effects of racial and ethnic stereotypes. In J. Bryant, \& M. B. Oliver (Eds.), Media effects advances in theory and research (pp. 325-341). New York, NY: Routledge.

Mastro, D. E., \& Behm-Morawitz, E. (2005). Latino representation on primetime television. Journalism \& Mass Communication Quarterly, 82(1), 110-130.

Mastro, D., Behm-Morawitz, E., \& Ortiz, M. (2007). The cultivation of social perceptions of Latinos: A mental models approach. Media Psychology, 9(2), 347-365.

Mastro, D. E., \& Greenberg, B. S. (2000). The portrayal of racial minorities on prime time television. Journal of Broadcasting and Electronic Media, 44(4), 690-703.

Mastro, D. E., Tukachinsky, R., Behm-Morawitz, E., \& Blecha, E. (2014). News coverage of immigration: The influence of exposure to linguistic bias in the news on consumer's racial/ethnic cognitions. Communication Quarterly, 62(2), 135-154.

McConnell, E. D. (2011). An "incredible number of Latinos and Asians:" Media representations of racial and ethnic population change in Atlanta, Georgia. Latino Studies, 9(2/3), 177-197.

Merskin, D. (2007). Three faces of Eva: Perpetuation of the hot-Latina stereotype in Desperate Housewives. Howard Journal of Communications, 18(2), 133-151.

Miville, M. L. (2010). Latina/o identity development: Updates on theory, measurement, and counseling implications. In J. G. Ponterotto, J. M. Casas, L. A. Suzuki, \& C. M. Alexander (Eds.), Handbook of multicultural counseling (3rd ed., pp. 241-252). Los Angeles, CA: Sage.

Nadler, J. T., \& Clark, M. H. (2011). Stereotype threat: A meta-analysis comparing African Americans to Hispanic Americans. Journal of Applied Social Psychology, 41(4), 872-890. 
Negrón-Muntaner, F. (2014). The Latino media gap: The state of Latinos in media. Report published for the National Association of Latino Independent Producers and the Center for the Study of Ethnicity and Race.

Nielsen, C. (2013). Wise Latina: Framing Sonia Sotomayor in the general-market and Latina/ooriented prestige press. Howard Journal of Communications, 24(2), 117-133.

Okamoto, D., Ebert, K., \& Violet, C. (2011). ¿El Campeón de Los Hispanos? Comparing the coverage of Latino/a collective action in Spanish- and English-language newspapers. Latino Studies, 9(2/3), 219-241.

O’Reilly, M., \& Parker, N. (2012). 'Unsatisfactory Saturation': a critical exploration of the notion of saturated sample sizes in qualitative research. Qualitative Research, 13(2), 1-8.

Perez-Stable, E. J., Hiatt, R. A., Sabogal, F., \& Otero-Sabogal, R. (1995). Use of Spanish surnames to identify Latinos: comparison to self-identification. Monographs-Journal of the National Cancer Institute, 18, 11-16.

Phinney, J. S. (1992). The multigroup ethnic identity measure: A new scale for use with diverse groups. Journal of Adolescent Research, 7(2), 156-176.

Ployhart, R. E., Ziegert, J. C., \& McFarland, L. A. (2003). Understanding racial differences on cognitive ability tests in selection contexts: An integration of stereotype threat and applicant reaction research. Human Performance, 16(3), 231-259.

Ramírez-Berg, C. (2002). Latino images in film: Stereotypes, subversions and resistance. Austin, TX: University of Texas Press.

Rivadeneyra, R. (2006). Do you see what I see?: Latino adolescents' perceptions of the images on television. Journal of Adolescent Research, 21(4), 393-414.

Rivadeneyra, R., Ward, L. M., \& Gordon, M. (2007). Distorted reflections: Media exposure and Latino adolescents' conceptions of self. Media Psychology, 9(2), 261-290.

Rodríguez, C. E. (2008). Heroes, lovers, and others: The story of Latinos in Hollywood. Oxford, England: Oxford University Press.

Rojas, V. (2004). The gender of Latinidad: Latinas speak about Hispanic television. The Communication Review, 7(2), 125-153.

Saenz, V. B., \& Ponjuan, L. (2009). The vanishing Latino male in higher education. Journal of Hispanic Higher Education, 8(1), 54-89.

Santa Ana, O. (2002). Brown tide rising: Metaphors of Latinos in contemporary American public discourse. Austin, TX: University of Texas Press.

Schmader, T., \& Johns, M. (2003). Converging evidence that stereotype threat reduces working memory capacity. Journal of Personality and Social Psychology, 85(3), 440-452.

Steele, C. M. (1997). A threat in the air: How stereotypes shape intellectual identity and performance. American Psychologist, 52(6), 613-629.

Steele, C. M., \& Aronson, J. (1995). Stereotype threat and the intellectual test performance of African Americans. Journal of Personality and Social Psychology, 69(5), 797-811.

Steinberg, S. L. (2004). Undocumented immigrants or illegal aliens? Southwestern media portrayals of Latino immigrants. Humboldt journal of Social Relations, 28(1), 109-133.

Suarez-Balcazar, Y., Balcazar, F., Taylor-Ritzler, T., Portillo, N., Rodakowsk, J., Garcia-Ramirez, M., \& Willis, C. (2011). Development and validation of the cultural competence assessment instrument: A factorial analysis. Journal of Rehabilitation, 77(1), 4-13.

Tajfel, H. (1978). Differentiation between social groups. London, England: Academic Press.

Tajfel, H., \& Turner, J. (1979). An integrative theory of intergroup conflict. In M. A. Hogg, \& D. Abrams (Eds.), Intergroup relations: Essential readings (pp. 94-104). Philadelphia, PA: Psychology Press.

Telzer, E. H., \& Vazquez Garcia, H. A. (2009). Skin color and self-perceptions of immigrant and U.S.-born Latinas: The moderating role of racial socialization and ethnic identity. Hispanic Journal of Behavioral Sciences, 31(3), 357-374. 
Torres, L., \& Ong, A. D. (2010). A daily diary investigation of latino ethnic identity, discrimination, and depression. Cultural Diversity and Ethnic Minority Psychology, 16(4), 561.

U.S. Census Bureau. (2015). QuickFacts: United States. Retrieved from: http://www. census.gov/quickfacts/table/PST045215/00

U.S. Department of Education. (2014). Graduation rate from first institution attended for firsttime, full-time bachelor's degree-seeking students at 4-source postsecondary institutions, by race/ethnicity, time to completion, sex, control of institution, and acceptance rate. Retrieved from: http://nces.ed.gov/programs/digest/d14/tables/dt14_326.10.asp

U.S. Department of Education. (2015). Bachelor's degrees conferred by postsecondary institutions, by race/ethnicity and sex of student: Selected sources, 1976-77 through 2013-14. Retrieved from http://nces.ed.gov/programs/digest/d15/tables/dt15_322.20.asp

Valdivia, A. N. (2010). Latina/os and the media. Cambridge, England: Polity.

Valentino, N. A., Brader, T., \& Jardina, A. E. (2013). Immigration opposition among U.S. Whites: General ethnocentrism or media priming of attitudes about Latinos? Political Psychology, 34(2), 149-166.

Vargas, L. (2009). Latina teens, migration, and popular culture. New York, NY: Peter Lang.

White, I. K. (2007). When race matters and when it doesn't: Racial group differences in response to racial cues. American Political Science Review, 101(2), 339-354. 